\title{
Modelling the chemical recycling of crosslinked poly (methyl methacrylate): kinetics of
}

depolymerisation

Simoní Da Ros ${ }^{a^{*}, 1}$, Rayany Stocco Braido ${ }^{a}$, Nathany Lisbôa de Souza e Castro ${ }^{a}$, Amanda L. T. Brandão $^{\mathrm{b}}$, Marcio Schwaab ${ }^{\mathrm{c}}$, José Carlos Pinto ${ }^{\mathrm{a}}$

a Programa de Engenharia Química/COPPE, Universidade Federal do Rio de Janeiro, Cidade Universitária, CP:68502, Rio de Janeiro, 21941-972, RJ, Brazil.

${ }^{\mathrm{b}}$ Departamento de Engenharia Química e de Materiais, Pontifícia Universidade Católica do Rio de Janeiro, 22451-900/38097, Brazil.

${ }^{c}$ Departamento de Engenharia Química, Universidade Federal do Rio Grande do Sul, Rua Engenheiro Luiz Englert, s/n - Prédio 12204, Porto Alegre, 90040-040, Brazil.

* Correspondence author

E-mail addresses: s.ros@ucl.ac.uk (correspondence author, S. Da Ros), rayany@peq.coppe.ufrj.br (R.S. Braido), nlisboa@eq.ufrj.br (N.L. de Souza e Castro), amanda.lemette@puc-rio.br (A. L. T. Brandão), schwaab@ufrgs.br (M. Schwaab), pinto@ peq.coppe.ufrj.br (J. C. Pinto) ONN London, UK. 


\section{ABSTRACT:}

Whereas increasing plastic solid waste production constitutes one of the main challenges of modern society, mainly due to the lack of suitable recycling technologies, chemical recycling represents an attractive solution for the conversion of plastic solid waste into valuable chemical intermediates. Herein, a kinetic model for the pyrolysis of a dental industry waste, ethylene glycol dimethacrylate (EGDMA) crosslinked poly (methyl methacrylate) (PMMA), is presented for the first time. Kinetics parameters and their statistical significance have been estimated from eight non-isothermal thermogravimetric analysis (TGA) experiments with heating rates varying between 5 and $50{ }^{\circ} \mathrm{C} \cdot \mathrm{min}^{-1}$ by using nonlinear regression. Our analysis indicates that the mechanism of depolymerisation of EGDMA crosslinked PMMA is likely to involve a consecutive reaction pathway involving two steps. The developed kinetic model containing five kinetic parameters only - was able to predict well all non-isothermal TGA runs, and was validated against isothermal TGA experiments at $400{ }^{\circ} \mathrm{C}$.

Keywords: plastic solid waste, chemical recycling, poly (methyl methacrylate), thermogravimetric analysis. 


\section{Introduction}

Since the first semi-synthetic polymer discoveries in the late $19^{\text {th }}$ century until the present day [1], plastics have revolutionised society by allowing the development of materials with the most diverse and unique properties, resulting in technological solutions with applications in a wide range of fields. Consequently, global plastic production has presented a remarkable rise, with figures ranging from 2 to 380 million metric tons (Mt) between 1950 and 2015 [2]. Concomitantly, global plastic solid waste production has also risen, totalling $150 \mathrm{Mt}$ per year, whereas recycling rates have remained unsatisfactorily low [3]. For example, according to the Association of Plastics Manufactures in Europe and the European Association of Plastics Recycling and Recovery Organisations, from the 27.1 Mt of plastic waste collected in Europe in 2016, only $31.1 \%$ was recycled, while $41.6 \%$ was burnt for energy recovery and $27.3 \%$ were disposed in landfills [4].

Low recycling rates and increasing plastic solid waste production constitute one of the main challenges of modern society, mainly due to the lack of suitable recycling technologies [3]. In this context, chemical recycling (or tertiary recycling) represents an attractive alternative because it allows for the conversion of plastic solid waste into valuable chemical intermediates $[5,6]$, thus contributing for the reduction of natural resources consumption and production of waste, while presenting potential for energy and monetary savings [3,7-9].

Poly (methyl methacrylate) (PMMA), is an industrially relevant polymer which finds unique applications, such as in its use in biomedical drug release systems, as optical fibers for light transmission, plastic eyeglass, contact lenses, denture materials, signs and displays, and liquid crystal displays (LCD) panels [7,10-12]. Due to its wide applicability, owing to its outstanding properties such as optical clarity, non-toxicity and resistance towards impact and most chemicals, PMMA demand is expected to grow over the coming years, with its market size projected to reach USD 8.16 billion by 2025 , imposing a pressure on its average price, 
which is already high when compared to common polymers, and increasing concerns on PMMA waste management $[8,9]$.

In the dental industry, ethylene glycol dimethacrylate (EGDMA) cross-linked PMMA is used to produce artificial teeth for dentures manufacturing, by moulding polymer disks in teeth shaped moulds. Substantial PMMA waste is produced in this moulding step, resulting in considerable losses, Fig. 1.1(a).

The recycling of PMMA waste has been assessed by different methods, including its direct reuse in the production of new polymers [13] and asphalt mixtures [14], and its mechanical $[9,15,16]$ and chemical $[9,11,17-19]$ recycling. Whereas the direct reuse of PMMA waste usually requires clean and uncontaminated streams, its mechanical recycling may allow for the processing of waste streams containing other types of plastics, however it usually results in polymers with inferior properties $[8,15]$. In contrast, the chemical recycling of PMMA by thermal pyrolysis has demonstrated great potential for the recovery of the methyl methacrylate (MMA) monomer [11,17-19], which can be further polymerised to result in polymer resins presenting comparable properties to those obtained by using virgin and non-recycled monomer $[17,18]$. Additionally, the PMMA pyrolysis can be suggested as a robust process, as impurities, such as different resins, can be separated in the MMA purification step by distillation [17] and have been reported to result in no significant impact on the MMA recovery yield [9].

However, in order to allow for the design, control and optimisation of a thermal pyrolysis reactor, a model able to describe the kinetics of depolymerisation is necessary. From this, the optimal operational conditions for an economically feasible recycling process can be established. Indeed, the kinetics of PMMA depolymerisation has long been investigated, with several experimental evidences pointing towards the paramount importance of the polymer structure on the depolymerisation mechanism [7,20-24]. 
When MMA is polymerised via free radical polymerisation in the absence of chain-transfer agents, combination and disproportionation termination reactions may lead to the formation of head-to-head linkages and vinylidene end groups throughout the final polymer structure $[20,22,23]$. In contrast, MMA anionic polymerisation, or free radical polymerisation in the presence of chain-transfer agents, does not lead to significant amounts of these irregular groups in the resultant PMMA [21]. Additionally, the synthesis of PMMA by using crosslinking additives may result in a further distinct polymer matrix [19,25,26]. Thus, different reaction pathways have been proposed to explain the free radical depolymerisation reaction network involved in the PMMA degradation.

According to some authors, the degradation process can be initiated by the breakdown of head-to-head linkages followed by end chain scissions associated to vinylidene end groups, when these structures are present in the polymer matrix [20], as illustrated in Fig.1.1(b-c). The end chain scission could occur due to the breaking of a carbon-carbon bond $\beta$ to the double bond, resulting in the formation of a monomer and a new vinylidene group in the remaining chain [20]. However, the above hypothesis has been contested, with the end chain scission initiation being explained by a radical transfer to the vinyl chain end instead [22], Fig.1.1(c). Regardless of the source of the radical, the dependence of this degradation step on the sample thickness has been demonstrated [22], supporting the role of radicals and their residence time within the polymer matrix. In the absence of irregular linkages, the degradation has been suggested to initiate by a random main chain scission process [20], Fig.1.1(d), although an initiation involving the homolytic scission of methoxycarbonyl side groups has also been supported [24]. Additionally, PMMA crosslinked with diallylmaleate and diallylphthalate has been suggested to depolymerise from the cross-linking points, whereas crosslinking with amines would favour random chain scission [25]. 


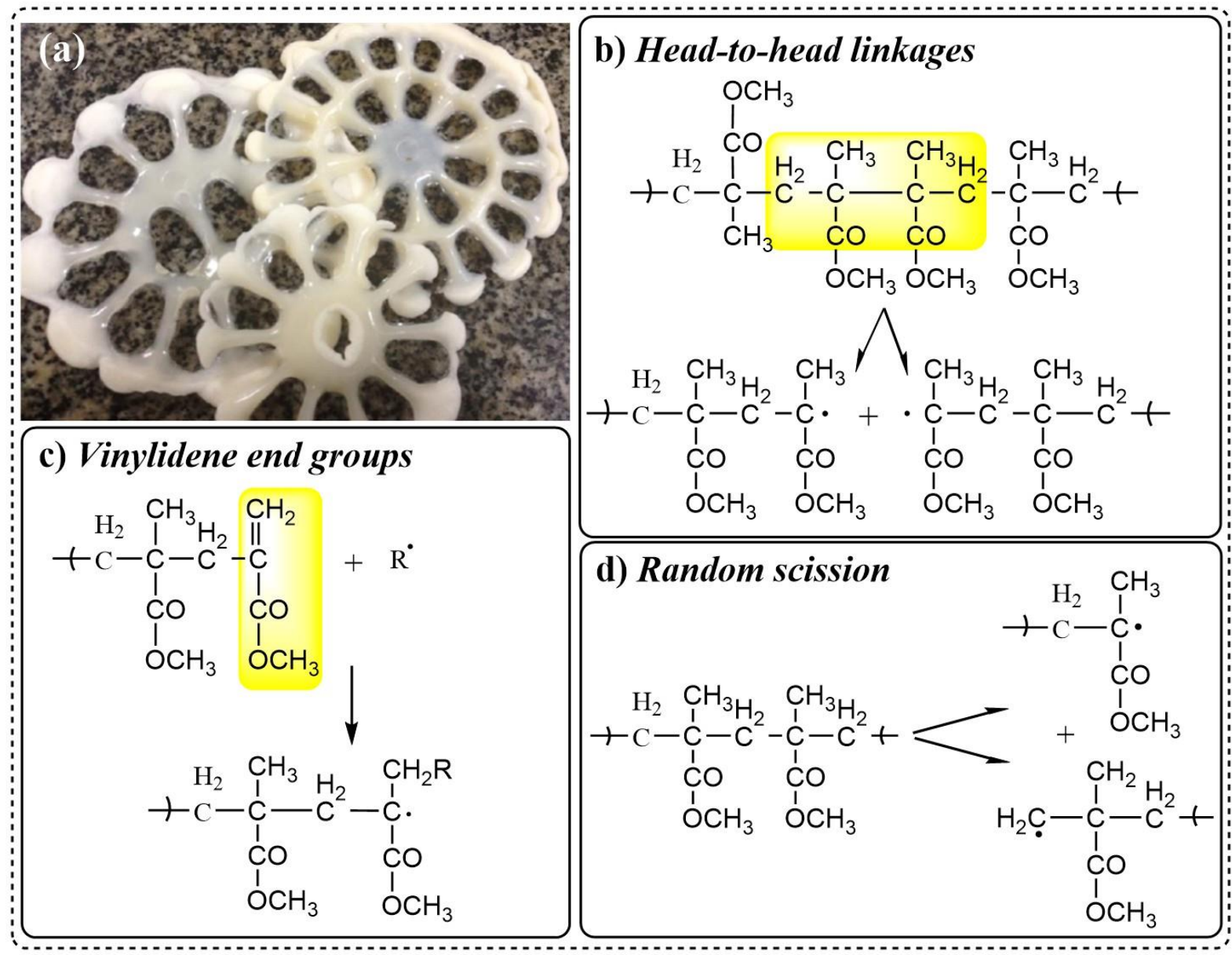

Fig. 1.1 - EGDMA crosslinked PMMA dental waste (a) and generally accepted initiation steps of the PMMA depolymerisation: breakage of head-to-head linkages (b), chain scission involving vinylidene end groups (c) and random main chain scissions (d) [20,22,23,27].

The proposed degradation steps have been supported by non-isothermal thermogravimetric analysis (TGA) [7,27,28]. For example, a model composed by four independent reaction steps and fifteen kinetic parameters has been reported to explain the thermal pyrolysis of PMMA prepared by free radical polymerisation [27]. In contrast, a model comprising four consecutive reaction steps and sixteen kinetic parameters has been proposed to explain the thermal degradation of PMMA under inert and oxidising environments [28].

However, the crosslinking effect on the PMMA depolymerisation kinetics has not been fully characterised, although some studies indicate a higher thermal stability associated to 
crosslinked PMMA [25]. In addition, it is important to note that even though TGA experiments are a powerful tool for kinetic characterisation of chemical reactions [29], kinetics parameters and the evaluation of their statistical significance are scarcely reported $[7,25,28]$, impairing the discrimination among reaction mechanisms $[30,31]$.

Thus, this work presents the modelling of the depolymerisation kinetics involved in the thermal pyrolysis of ethylene glycol dimethacrylate (EGDMA) crosslinked PMMA from industrial dental waste for the first time. Kinetics parameters and their statistical significance have been determined by using eight non-isothermal TGA experiments with heating rates varying between 5 and $50{ }^{\circ} \mathrm{C} \cdot \mathrm{min}^{-1}$. Our analysis indicates that the mechanism of depolymerisation of EGDMA crosslinked PMMA is likely to involve a consecutive reaction pathway involving two steps. The developed kinetic model - containing five kinetic parameters only - was able to predict well all non-isothermal TGA runs, and was validated against isothermal TGA experiments at $400{ }^{\circ} \mathrm{C}$.

\section{Materials and Methods}

\subsection{Materials}

PMMA-based artificial teeth scraps produced by a dental industry, as illustrated in the Fig. 1.1(a), were studied in its original form, with pieces diameters ranging from 1 to $10 \mathrm{~mm}$. The PMMA waste samples contained $1 \mathrm{wt} . \%$ of titanium oxide $\left(\mathrm{TiO}_{2}\right)$ and around $5 \mathrm{wt} . \%$ of the cross-linking agent ethylene glycol dimethacrylate (EGDMA), as described elsewhere [17]. For comparison, a homopolymer PMMA powder with particle average size below $200 \mu \mathrm{m}$ produced by the same industry was also evaluated.

\subsection{Thermogravimetric Experiments}


Non-isothermal thermogravimetric analysis of the PMMA scraps was performed in a TGA STA 6000 equipment (Mettler Toledo, Ohio, USA), under nitrogen flow $\left(20 \mathrm{~mL} \cdot \mathrm{min}^{-1}\right)$, at heating rates of $5,10,15,25$ and $50{ }^{\circ} \mathrm{C} \cdot \mathrm{min}^{-1}$. Samples $(\sim 10 \mathrm{mg})$ were heated from 50 to $650{ }^{\circ} \mathrm{C}$ and kept at the final temperature for $5 \mathrm{~min}$. In order to confirm the reproducibility of the thermogravimetric runs, four replicates were performed at the heating rate of $5{ }^{\circ} \mathrm{C} \cdot \mathrm{min}^{-1}$.

Isothermal thermogravimetric analysis of the PMMA scraps was performed as described above at 300,350 and $450{ }^{\circ} \mathrm{C}$. Samples were heated from $50{ }^{\circ} \mathrm{C}$ to the final temperature with a heating rate of $100{ }^{\circ} \mathrm{C} \cdot \mathrm{min}^{-1}$ and kept at the final temperature for $4.5 \mathrm{~h}$.

\subsection{Mathematical Modelling of PMMA Kinetics of Depolymerisation}

The aluminium sample holder was modelled as a batch reactor for the solid phase, as the atmospheric composition just above the crucible was kept essentially constant by the inert gas flow. The kinetics of depolymerisation was investigated by using two different modelling approaches, involving up to three irreversible reaction steps. In the first approach, independent reactions were described assuming a first-order rate for the polymer mass, whereas consecutive steps were considered in the second approach, Table 2.1 .

Table 2.1 - Elementary reactions considered in the EGDMA crosslinked PMMA thermal depolymerisation.

\begin{tabular}{ll|ll}
\hline Independent reactions & & Consecutive reactions & \\
\hline$P_{1} \stackrel{k_{1}}{\longrightarrow} V$ & (a1) & $P_{1} \stackrel{k_{1}}{\longrightarrow} P_{2}+V$ & (b1) \\
$P_{2} \stackrel{k_{2}}{\longrightarrow} V$ & (a2) & $P_{2} \stackrel{k_{2}}{\longrightarrow} P_{3}+V$ & (b2) \\
$P_{3} \stackrel{k_{3}}{\longrightarrow} V$ & (a3) & $P_{3} \stackrel{k_{3}}{\longrightarrow} V$ & (b3) \\
\hline
\end{tabular}


Thus, the independent reaction network assumed the simultaneous depolymerisation of different polymer chains into volatiles species (V). In contrast, the consecutive reaction mechanism assumed the formation of intermediary polymer species which undergo further depolymerisation.

The consumption rate of an elementary step in the solid phase was calculated through the law of mass action according to Eq. (2.1), where $k_{j}$ is the rate constant of reaction $j$ and $P_{i}$ is the mass of polymer chains of type $i$.

$$
r_{j}=k_{j} P_{i=j}
$$

The net reaction rate was calculated in accordance to Eq. (2.2), where $N R$ is the number of reactions considered in the global model (from 1 to 3 ) and $v_{i, j}$ is the stoichiometric coefficient of the component $i$ in the reaction $j$, negative for the reactant and positive for the product.

$$
R_{i}=\sum_{j=1}^{N R} v_{j, i} r_{j}
$$

The mass of the polymer chains of type $i, P_{i}$, was normalised by the initial mass of the polymer, $P_{0}$, resulting in the system of ordinary differential equations represented by Eq. (2.32.4 ), where $\varepsilon_{i}$ is the mass fraction of polymer chains of type $i, P$ is the total mass of polymer at any time, and $N P$ is the number of different types of polymer chains considered (from 1 to 3 ).

$$
\begin{aligned}
& \frac{d \varepsilon_{i}}{d t}=R_{i} \\
& \frac{d P}{d t}=P_{0} \sum_{i=1}^{N P} \frac{d \varepsilon_{i}}{d t}
\end{aligned}
$$


The dependence of the reaction rate constant, $k_{j}$, towards temperature was described by the reparameterised Arrhenius equation, Eq. (2.5) [32,33]. In Eq. (2.5), $T$ is the measured temperature, and $T_{r e f}$ was defined as equal to $325^{\circ} \mathrm{C}$.

$$
k_{j}=\exp \left(A_{T r e f, j}+B_{j}\left(\frac{T-T_{r e f}}{T}\right)\right)
$$

The $A_{\text {Tref }}$ constant is related to the pre-exponential factor of the original Arrhenius equation, $k_{0}$, according to Eq. (2.6) and $B_{j}$ relates to the activation energy, $E$, according to Eq. (2.7).

$$
\begin{aligned}
& A_{\text {Tref }, j}=\ln \left(k_{0, j}\right)-\frac{E_{j}}{R \cdot T_{r e f}} \\
& B_{j}=\frac{E_{j}}{R \cdot T_{r e f}}
\end{aligned}
$$

The number of reactions in the independent and consecutive modelling approaches, Table 2.1, was varied from one to three during the model development process, resulting in five different kinetic models that were tested against the experimental data. Thus, the number of kinetic optimization variables was equal to six when three reactions were considered $\left(A_{T r e f, 1}\right.$, $\left.B_{1}, A_{T r e f, 2}, B_{2}, A_{T r e f, 3}, B_{3}\right)$, equal to four when two reactions were considered (A $A_{\text {Tref, },}, B_{1}, A_{\text {Tref, } 2 \text {, }}$ $\left.B_{2}\right)$ and equal to two when only one reaction was evaluated $\left(A_{\operatorname{Tref}, 1}, B_{1}\right)$. Additionally, for both modelling approaches, NP-1 mass fractions were estimated as initial condition for the ordinary differential equations, Eq. (2.3), being the sum of all mass fractions, at any time, equal to 1. The initial mass of the polymer, $P_{0}$, was also estimated, resulting in a total of $2 \cdot N R+N R$ parameters which were estimated from experimental data. Thus, for the modelling approach involving consecutive reactions, all initial mass fractions were allowed to be different from 
zero, implying that the initial polymer could already contain degraded chains at the beginning of pyrolysis. Finally, it should also be noted that the heating rate was not explicitly presented in the model equations because the temperature used in the model calculations was the actual measured value $[29,34]$.

\subsection{Parameter Estimation}

The ordinary differential equations were solved numerically using the backward differentiation technique available in DASSL code [35], with relative and absolute tolerances equal to $10^{-5}$. The parameter estimation procedure consisted in the search of the best set of parameter estimates, $\theta$, throughout the minimisation of the least-squares objective function, $F_{o b j}$, Eq. (2.8). In the Eq. (2.8), $N E$ is the number of experimental data points, $\mathrm{P}_{i}^{\exp }$ denotes the experimental mass recorded during the thermogravimetric run, $\mathrm{P}_{i}^{\text {mod }}$ is the value calculated using Eq. (2.4), and $x_{i}^{\text {mod }}$ represents the experimental condition of time and temperature.

$$
F_{o b j}=\sum_{i=1}^{N E}\left(P_{i}^{\exp }-P_{i}^{\bmod }\left(x_{i}^{\bmod }, \theta\right)\right)^{2}
$$

The minimisation of Eq. (2.8) was performed using a hybrid optimisation method implemented in Fortran 90, in which the Particle Swarm Optimization algorithm [36] is used in the initial phase of minimisation $[37,38]$. The best estimate of the point of the minimum is used as an initial guess for a second estimation round, using the Gauss-Newton method [31,39]. Thirty particles were used, and at least 1000 iterations were performed, resulting in at least 30000 evaluations of the objective function. Convergence was achieved when the relative modification of the objective function was smaller than $1.0 \times 10^{-6}$. Statistical significance of model parameters was evaluated with the standard t-test [40], with $95 \%$ confidence level. The evaluation of the model adequacy was performed by comparing models prediction variance, 
$\sigma_{m}^{2}$, as defined in accordance to Eq. (2.9), with the help of the standard F-test [31,40]. In Eq. (2.9), $F_{o b j}$ is the value of the objective function at its point of minimum, $N E$ is the number of experimental data points and NPar is the number of parameters estimated for the model $\mathrm{m}$.

$$
\sigma_{m}^{2}=\frac{F_{o b j}}{(N E-N P a r)}
$$

\subsection{Experimental Data Treatment}

To reduce the computational effort required for the minimisation of the objective function during the parameter estimation procedure, in this work, the experimental data was sampled as recommended by Conesa et al. (2001) [34]. This procedure was found necessary due to the high recording frequency of the TGA instrument, which resulted in thermograms containing up to 45000 data points per experiment, depending on the heating rate. Thus, typically, the sampling procedure applied collected 1 data point for every 5 in the thermogram regions of small and slow weight loss (up to nearly $200{ }^{\circ} \mathrm{C}$ ) and it collected 3 data points for every 5 in the range of fast weight loss (above $200{ }^{\circ} \mathrm{C}$ ), as it is illustrated in the Fig. $\mathrm{S} 1$ of the Supporting Information (SI).

\section{Results and Discussion}

The good reproducibility of the thermogravimetric runs was confirmed by four identical experiments performed using the EGDMA crosslinked PMMA scraps with heating rates equal

to $5{ }^{\circ} \mathrm{C} \cdot \mathrm{min}^{-1}$, as illustrated in the Fig. 3.1. For comparison, the thermogravimetric profile of the homopolymer PMMA is also shown. 


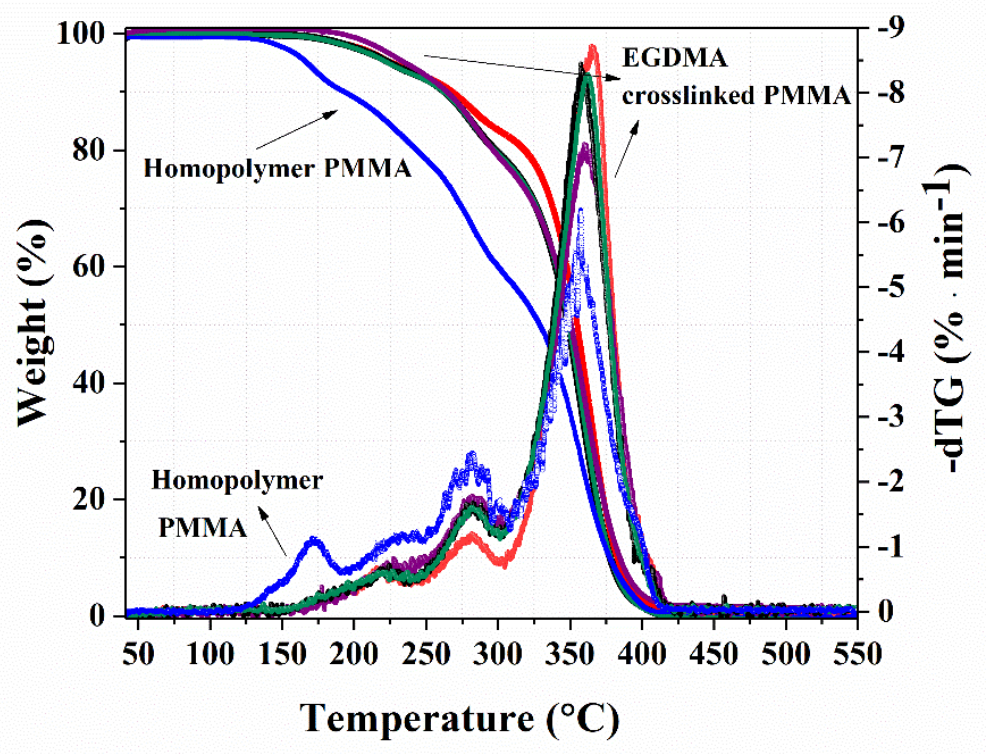

Fig. 3.1 - Replicates of TGA thermogravimetric thermograms for the EGDMA crosslinked ( $\bullet$, $\bullet, \bullet, \bullet)$ and homopolymer PMMA $(\bullet)$ at $5^{\circ} \mathrm{C} \cdot \min ^{-1}$.

As expected, the EGDMA crosslinked PMMA exhibited a higher thermal stability in comparison to its counterpart homopolymer, with main weight loss processes being observed above $200{ }^{\circ} \mathrm{C}$. Moreover, up to three degradation processes could be associated to the weight loss steps, as suggested by the presence of three points of maximum in the thermogram derivative, illustrated in the Fig. 3.1 (right Y-axis). In contrast, the homopolymer PMMA started to degrade around $150{ }^{\circ} \mathrm{C}$ and presented a distinct thermogram profile, in which four points of maximum could be observed in the thermogram derivative, suggesting the presence of up to four processes of degradation, as also observed by other authors [27].

As discussed previously, the PMMA depolymerisation steps may involve the breakdown of head-to-head linkages, chain scissions associated to vinylidene end groups, random main chain scissions, methoxycarbonyl side groups scissions and cross-linking points scission, depending on the polymer structure $[20,22,24,25]$. For the EGDMA crosslinked PMMA dental waste investigated in this work, whereas the main degradation process could be associated to main chain random scissions, which could also involve methoxycarbonyl side 
groups scissions, the processes observed at lower temperatures could be associated to the combined effect of different degradation steps, which could involve scissions of cross-linking points and chain scissions associated with vinylidene end groups. Therefore, it was an objective of this study to develop a kinetic model able to predict the depolymerisation kinetics of EGDMA crosslinked PMMA. To achieve this, two modelling approaches were investigated, as illustrated in Table 2.1 from Section 2.3. In the first modelling approach, up to three independent reactions were evaluated [7,25,27], while in the second, up to three consecutive and dependent reactions were considered [7,28]. Each model was fitted to the experimental data and the statistical significance of the estimative parameters was assessed.

\subsection{The Three Degradation Reaction Steps Models}

The use of a three degradation reaction steps model (in both modelling approaches) resulted in a good fit of the experimental data, with linear correlation coefficients always higher than 0.99, as it is illustrated in Fig. S2 of the SI. Nevertheless, in both cases, some of the kinetic parameters were verified to present no statistical significance, indicating that the evaluated models could be overparameterised and that the hypothesis of a depolymerisation process involving three degradation reaction steps, as described by Eq. (2.1-2.4), could be unrealistic. It should be noted that the total number of parameters estimated from experimental data when three degradation steps were considered was equal to nine for both modelling approaches. The finding that some of these parameters were not statistically significant is very surprising, since up to sixteen kinetic parameters have been used to explain the depolymerisation kinetics of PMMA prepared by free radical polymerisation $[27,28]$. Thus, it is possible to conclude that the depolymerisation kinetics of EGDMA crosslinked PMMA should be distinct from its counterpart pure homopolymer, as it is indeed the case indicated by our experiments, Fig. 3.1. 


\subsection{The Two Degradation Reaction Steps Models}

When a two degradation reaction steps model was evaluated, both modelling approaches were able to represent well the experimental data and all kinetic parameters were found to be statistically meaningful, as it is illustrated in the Fig. 3.2 and Table 3.1 for the consecutive reaction modelling approach.
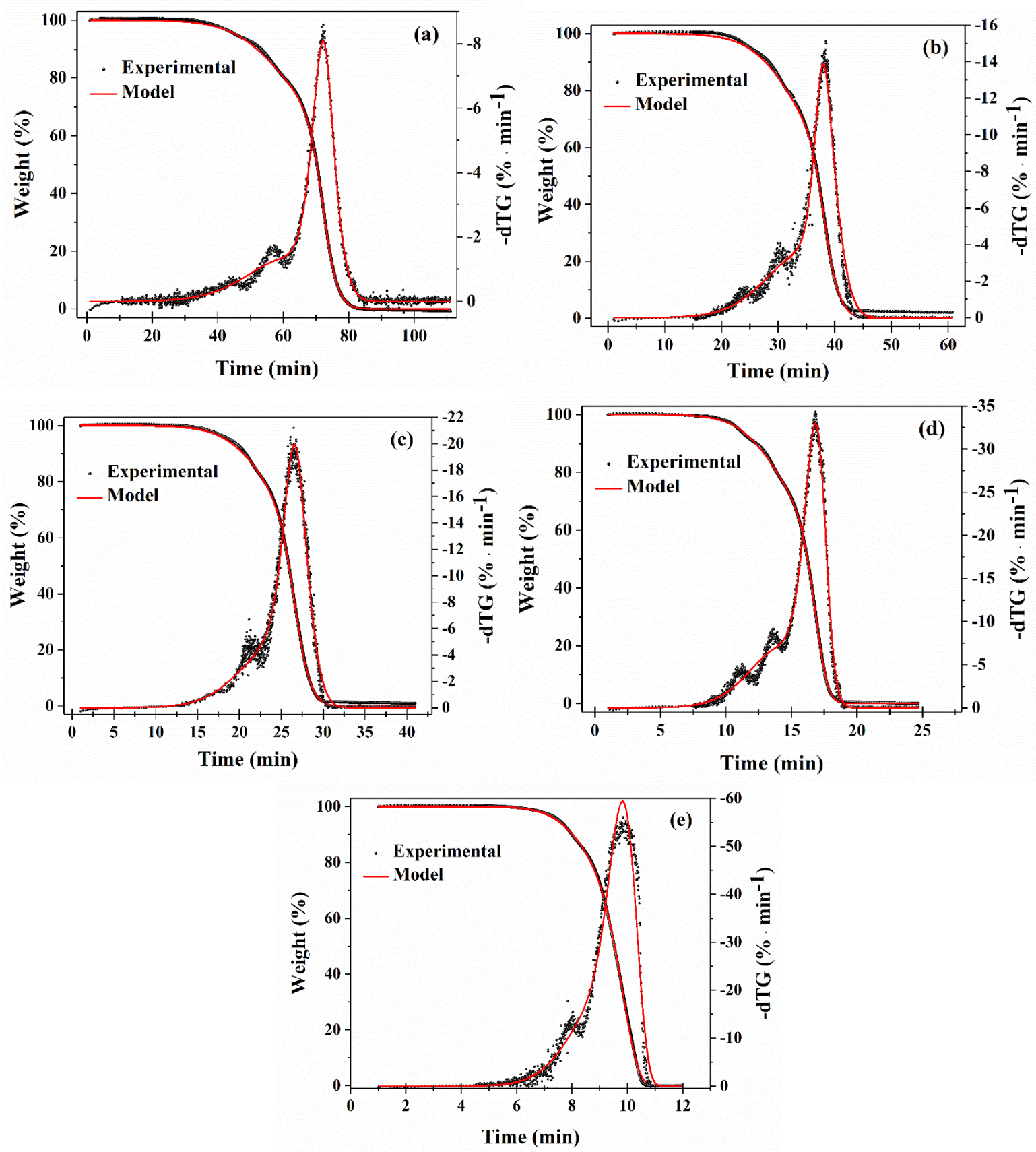
Fig. 3.2 - Experimental thermogravimetric profiles $(\bullet)$ and the two consecutive degradation steps model (-) at the heating rates equal to 5 (a), 10 (b), 15 (c), 25 (d) and 50 (e) ${ }^{\circ} \mathrm{C} \cdot \mathrm{min}^{-1}$. Kinetics parameters are summarised in Table 3.1.

However, the evaluation of the parameter estimates demonstrated that the hypothesis of a two independent degradation reaction steps led to kinetic estimates highly correlated with the heating rate, while that much smaller correlations could be verified for kinetic parameters estimated considering the two consecutive reactions model, as it is illustrated in the Fig. 3.3. For instance, the linear correlation coefficient, $\rho$, between the kinetic parameter estimate $A_{\text {Tref, } 1}$ and the heating rate could be calculated as equal to 0.99 while considering the independent reaction modelling approach and as equal to 0.52 when considering the consecutive reaction model, Fig. 3.3 (a).

Whereas the effect of heating rate on the kinetic parameter estimates may indicate that heat transfer processes influenced the pyrolysis kinetics [34], it can be suggested that the appropriate choice of the kinetic reaction pathway may minimise the influence of heat transfer effects on the obtained kinetic parameters.

Table 3.1 also presents the initial mass fraction and polymer mass which were estimated from the experimental data for the consecutive reaction modelling approach. The initial mass estimated represented very well the initial experimental mass used in the TGA runs, as it is illustrated in Fig. 3.2. In addition, the initial mass fraction of polymer chains, as calculated by considering the two consecutive degradation steps model, indicated that up to $30 \mathrm{wt} \%$, in average, of polymer chains could already be degraded to some extent before the start of pyrolysis. As observed for the kinetic parameters, the two consecutive reactions model allowed for the estimation of initial mass fractions which were not correlated to the heating rate, in 
contrast to the mass fractions estimated by using the independent reaction model, which demonstrated significant correlation with the heating rate, as it is illustrated in the Fig. 3.3 (e).

Table 3.1 - Kinetic parameters estimates and their standard deviations obtained from experimental thermograms for the two consecutive degradation steps model.

\begin{tabular}{|c|c|c|c|c|c|c|c|}
\hline Exp. & $\beta^{\mathrm{a}}$ & $A_{\text {Tref, }, 1}$ & $B_{1}$ & $A_{\text {Tref, } 2}$ & $B_{2}$ & $\varepsilon_{1,0}$ & $\begin{array}{c}P_{0} \\
(\mathrm{mg})\end{array}$ \\
\hline 1 & 5 & $-3.12 \pm 0.01$ & $25.51 \pm 0.19$ & $-0.52 \pm 0.09$ & $14.09 \pm 0.34$ & $0.79 \pm 0.004$ & 6.09 \\
\hline 2 & 5 & $-2.73 \pm 0.005$ & $40.97 \pm 0.33$ & $-1.74 \pm 0.007$ & $10.31 \pm 0.02$ & $0.70 \pm 0.002$ & 8.60 \\
\hline 3 & 5 & $-2.87 \pm 0.006$ & $43.86 \pm 0.33$ & $-1.76 \pm 0.006$ & $9.25 \pm 0.03$ & $0.77 \pm 0.001$ & 11.22 \\
\hline 4 & 5 & $-2.64 \pm 0.006$ & $43.34 \pm 0.41$ & $-1.77 \pm 0.007$ & $10.43 \pm 0.03$ & $0.69 \pm 0.002$ & 6.76 \\
\hline 5 & 10 & $-2.90 \pm 0.04$ & $49.73 \pm 1.27$ & $-1.61 \pm 0.01$ & $10.64 \pm 0.06$ & $0.58 \pm 0.004$ & 7.20 \\
\hline 6 & 15 & $-2.54 \pm 0.03$ & $37.72 \pm 0.69$ & $-1.40 \pm 0.01$ & $11.31 \pm 0.09$ & $0.64 \pm 0.006$ & 11.13 \\
\hline 7 & 25 & $-2.37 \pm 0.01$ & $33.12 \pm 0.31$ & $-0.40 \pm 0.01$ & $10.65 \pm 0.04$ & $0.68 \pm 0.003$ & 10.61 \\
\hline 8 & 50 & $-2.60 \pm 0.04$ & $25.32 \pm 0.28$ & $-0.25 \pm 0.12$ & $14.11 \pm 0.38$ & $0.77 \pm 0.02$ & 10.68 \\
\hline & & $-2.72 \pm 0.24$ & $37.44 \pm 8.8$ & $-1.18 \pm 0.67$ & $11.35 \pm 1$. & $0.70 \pm 0.07$ & \\
\hline
\end{tabular}

${ }^{\mathrm{a}}$ Heating rate $\left(\right.$ in $\left.{ }^{\circ} \mathrm{C} \cdot \mathrm{min}^{-1}\right)$.
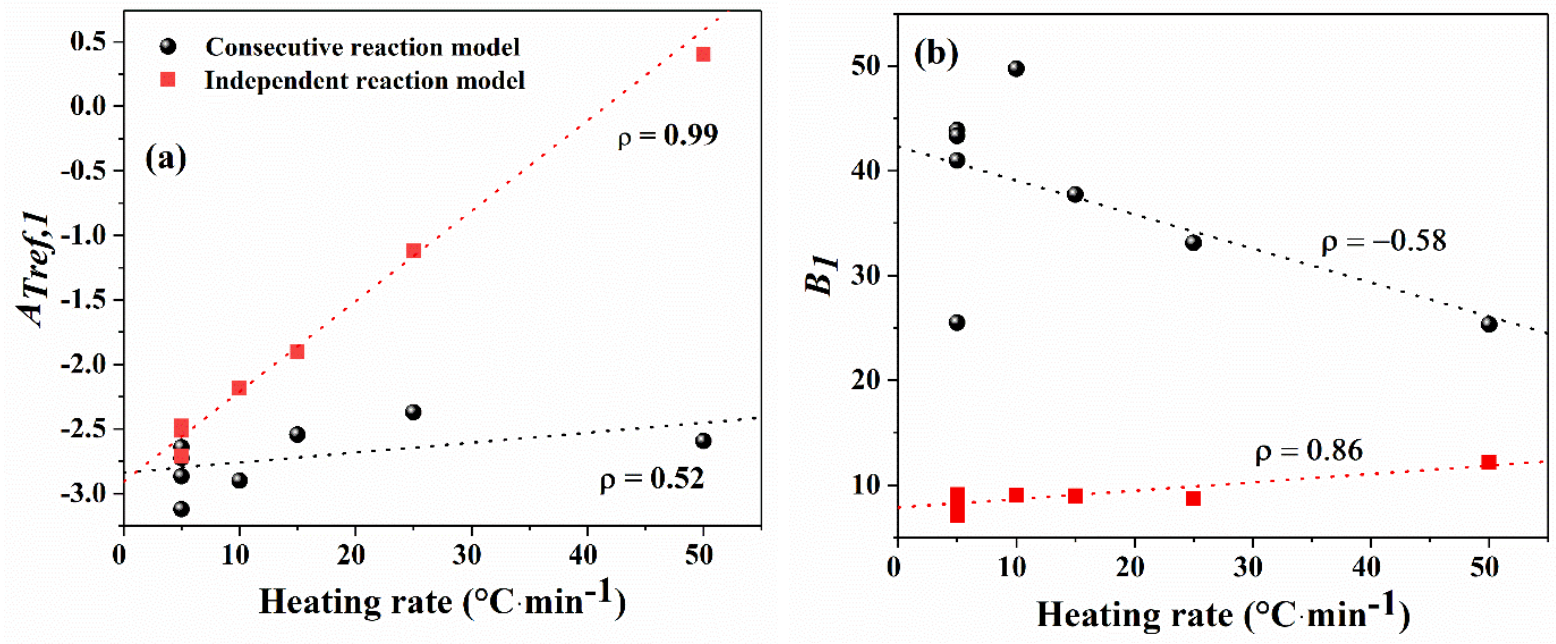

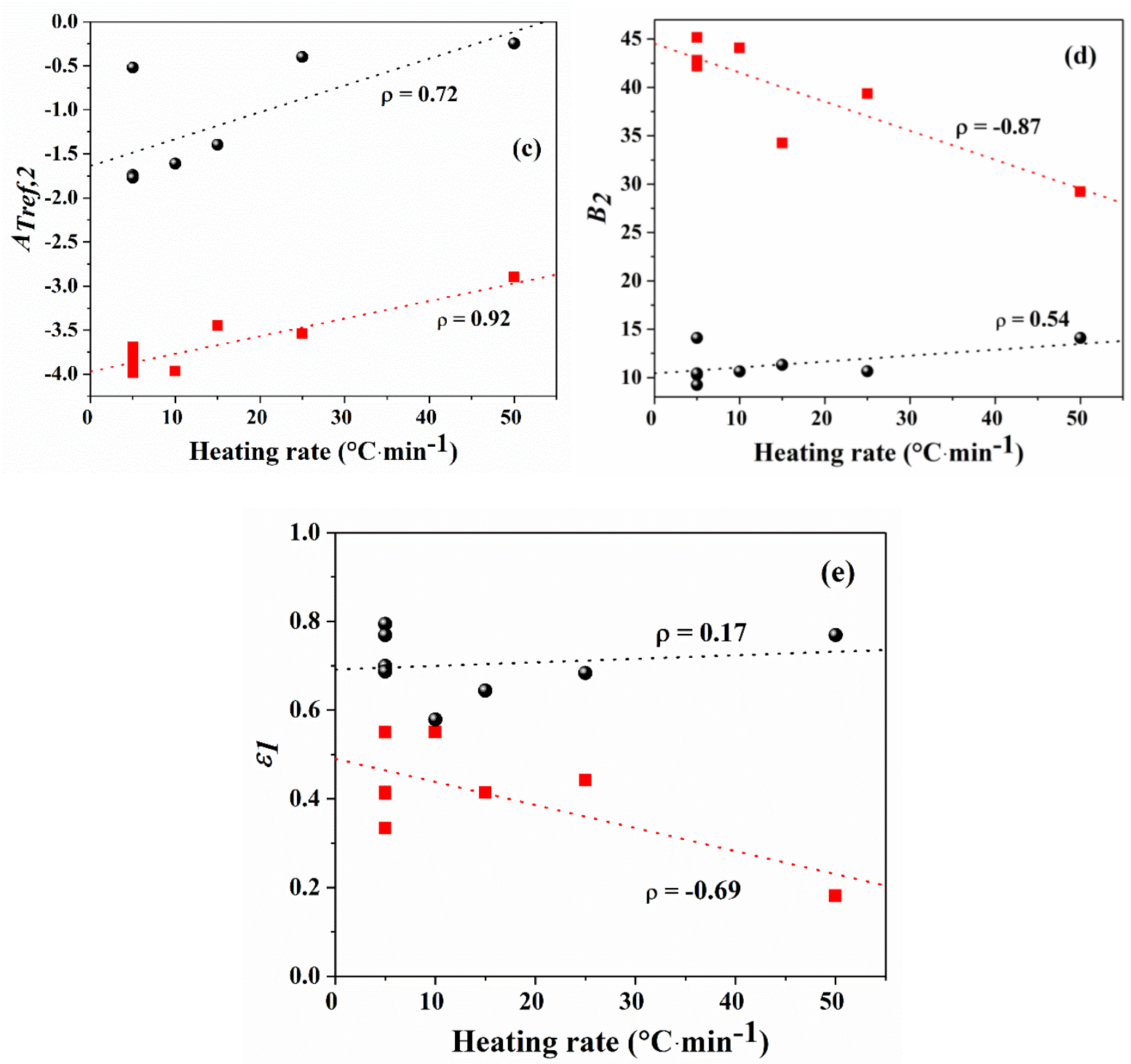

Fig. 3.3 - Linear correlation relationship between the kinetic parameter $A_{\operatorname{Tref}, 1}$ (a), $B_{1}$ (b), $A_{\text {Tref, } 2}$ (c), $B_{2}(\mathrm{~d})$, the initial mass fraction, $\varepsilon_{1}$, (e), and the heating rate for the independent ( $\square$ ) and consecutive $(\bullet)$ reactions model approaches. Note how linear correlation coefficients $(\rho)$ are always lower when the two consecutive degradation steps model is considered.

From the average values presented in Table 3.1, the activation energy and the preexponential values were calculated with the help of Eq. (2.6-2.7) and their values are presented in Table 3.2. 
Table 3.2 - Activation energies and pre-exponential factors calculated from kinetic parameter estimates for the two consecutive degradation steps model of EGDMA crosslinked PMMA pyrolysis.

\begin{tabular}{lcc}
\hline & $\boldsymbol{E}\left(\mathrm{kJ} \cdot \mathrm{mol}^{-1}\right)$ & $\boldsymbol{k}_{\boldsymbol{0}}\left(\mathrm{min}^{-1}\right)$ \\
\hline Depolymerisation reaction (b1) & 186.21 & $2.01 \times 10^{13}$ \\
$P_{1} \stackrel{k_{1}}{\longrightarrow} P_{2}+V$ & & \\
Depolymerisation reaction (b2) & 56.44 & $4.35 \times 10^{2}$ \\
$P_{2} \stackrel{k_{2}}{\longrightarrow} P_{3}+V$ & & \\
\hline
\end{tabular}

The activation energy for the random scission depolymerisation step of PMMA pyrolysis has been reported as equal to 200 [27], 210 [41] and $161 \mathrm{~kJ} \cdot \mathrm{mol}^{-1}$ [28], whereas the end-chain scission activation energy has been reported as equal to $154 \mathrm{~kJ} \cdot \mathrm{mol}^{-1}$ [21]. Thus, it can be suggested that the crosslinking agent may reduce the activation energy of one of the degradation steps in the case of the EGDMA crosslinked PMMA pyrolysis.

Finally, it should be noted that despite the presence of $1 \mathrm{wt} . \%$ of $\mathrm{TiO}_{2}$ in the EGDMA crosslinked PMMA dental waste, which is used as a reinforcement agent for improving mechanical properties of the dental PMMA resin [42], no catalytic effect of $\mathrm{TiO}_{2}$ on the depolymerisation kinetics has been observed, as indicated by the thermogravimetric analysis of EGDMA crosslinked PMMA containing no $\mathrm{TiO}_{2}[43,44]$, Fig. $\mathrm{S} 4$ in the $S I$, and by the kinetic parameters estimated from the above experimental data for the two consecutive degradation steps model, Table S1 in the SI.

\subsection{The One Degradation Step Model}

The hypothesis of only one degradation reaction step, involving the depolymerisation of polymer chains $P_{i}$ into volatiles, was also investigated. In this case, modelling approaches become the same, and the number of parameters which require estimation from experimental 
data is equal to three $\left(A_{T r e f, 1}, B_{1}\right.$ and the initial condition of the ordinary differential equation). The fitting of this model to the thermograms obtained at the different heating rates also resulted in high linear correlation coefficients between experimental data and model predictions, always higher than 0.99, indicating a good fit. However, the comparison of the model prediction variance between the different models, that is, the model containing one degradation step and the model containing two consecutive degradation steps, with the help of the standard test-F $[31,39,40]$, indicates a significant loss of quality fit when only one degradation step is considered. Thus, the modelling approach involving two consecutive reaction steps seems to be the most promising to represent the pyrolysis of EGDMA crosslinked PMMA.

\subsection{Simulation and Model Validation}

Fig. 3.4 shows the conversion as a function of pyrolysis time calculated by the simulation of the two consecutive degradation steps model at different temperatures.

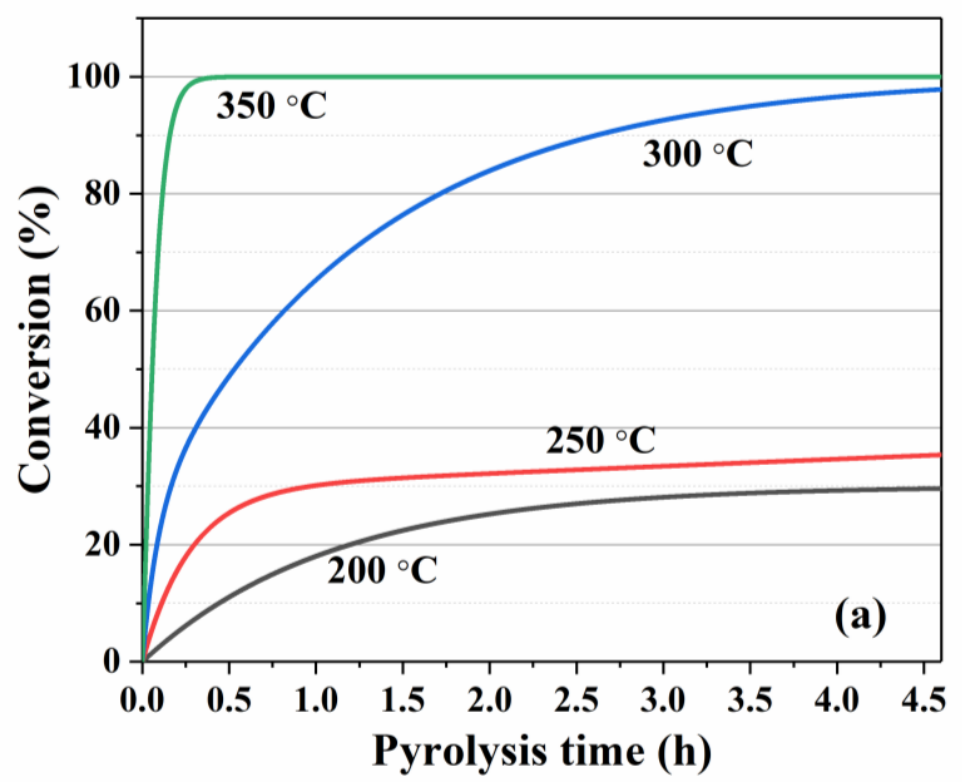

Fig. 3.4 - Simulation of EGDMA crosslinked PMMA pyrolysis conversion as a function of time at $200,250,300$, and $350{ }^{\circ} \mathrm{C}$. 
As expected, the model indicates that the amount of depolymerised PMMA increases as a function of time and temperature. Moreover, the conversion reaches a plateau at around $30 \%$ at temperatures between 200 and $250{ }^{\circ} \mathrm{C}$, indicating that higher temperatures are required for the complete pyrolysis conversion of EGDMA crosslinked PMMA, in line with thermograms presented in Fig. 3.1 and previous findings from Braido et al (2018) [17].

For the validation of the two consecutive degradation steps model, isothermal TGA experiments were carried out at 300,350 and $400{ }^{\circ} \mathrm{C}$, as described in the Section 2.2. Additionally, mass conversions reported by Braido et al (2018) [17], who investigated the thermal pyrolysis of EGDMA crosslinked PMMA dental waste at isothermal conditions using a larger scale of $30 \mathrm{~g}$, were further used to assess the system behaviour. Table 3.3 compares the experimental mass conversions obtained from the isothermal TGA runs performed in this work with the values obtained for the larger scale process (from [17]), after 1, 1.5 and $2 \mathrm{~h}$ of isothermal processing at different temperatures. Full experimental isothermal thermograms are presented in the Fig. S3 of the SI.

Table 3.3 - Experimental mass conversion, $X$, (in \%) for the isothermal pyrolysis of EGDMA crosslinked PMMA at 300,350 and $400{ }^{\circ} \mathrm{C}$.

Pyrolysis Temperature $\left({ }^{\circ} \mathrm{C}\right)$

\begin{tabular}{|c|c|c|c|c|c|c|}
\hline \multirow[t]{2}{*}{ Scale } & \multicolumn{2}{|c|}{300} & \multicolumn{2}{|c|}{350} & \multicolumn{2}{|c|}{400} \\
\hline & Time $(h)$ & $X(\%)$ & Time $(h)$ & $X(\%)$ & Time $(h)$ & $X(\%)$ \\
\hline $10 \mathrm{mg}$ & 1 & 64.66 & 1.5 & 98.67 & 1 & 100 \\
\hline $10 \mathrm{mg}$ & 2 & 73.20 & & & & \\
\hline $30 \mathrm{~g}^{\mathrm{a}}$ & 1 & $38.99^{\mathrm{a}}$ & 1.5 & $72.70^{\mathrm{a}}$ & 1 & $96.71^{\mathrm{a}}$ \\
\hline $30 \mathrm{~g}^{\mathrm{a}}$ & 2 & $33.80^{\mathrm{a}}$ & & & 2 & $99.08^{\mathrm{a}}$ \\
\hline
\end{tabular}

${ }^{\mathrm{a}}$ Data from Braido et al (2018) [17]. 
Conversions reported for the larger scale process were significantly smaller than the ones obtained in the isothermal TGA experiments at 300 and $350{ }^{\circ} \mathrm{C}$, suggesting that thermal effects may play an important role in the EGDMA crosslinked PMMA pyrolysis at these lower temperatures. In contrast, experimental mass conversions obtained at $400{ }^{\circ} \mathrm{C}$ demonstrated a better agreement between the two process scales, suggesting that at this higher temperature the pyrolysis kinetics may be favoured, reducing the importance of thermal effects.

As the two consecutive degradation steps model developed in this work assumes uniform chemical composition and energy distribution within the solid dental waste under pyrolysis, that is, a system with no mass or energy transfer constraints, we have used the isothermal TGA experimental data obtained at $400{ }^{\circ} \mathrm{C}$ for the model validation. Fig. 3.5(a) illustrates the excellent agreement between the two consecutive degradation steps model predictions and the isothermal experimental data at $400{ }^{\circ} \mathrm{C}$. Fig.3.5(b) further presents the absolute differences between simulated and experimentally observed mass conversions, $\Delta X$, from the isothermal TGA experiments. Whereas the model overestimates mass conversions at $300{ }^{\circ} \mathrm{C}$, the absolute difference between calculated and observed mass conversions is exponentially decreased from 6.41 to $0.43 \%$ as a function of pyrolysis time at $350{ }^{\circ} \mathrm{C}$, and is zero at $400{ }^{\circ} \mathrm{C}$, emphasising the increased model ability for describing the EGDMA crosslinked PMMA pyrolysis as temperature increases from 300 to $400{ }^{\circ} \mathrm{C}$.

Therefore, whereas model simulations presented in Fig 3.4 explains the two consecutive degradation steps model behaviour, its application towards larger industrial scales may require the consideration of energy transfer constraints, in particular for process temperatures lower than $400{ }^{\circ} \mathrm{C}$. 

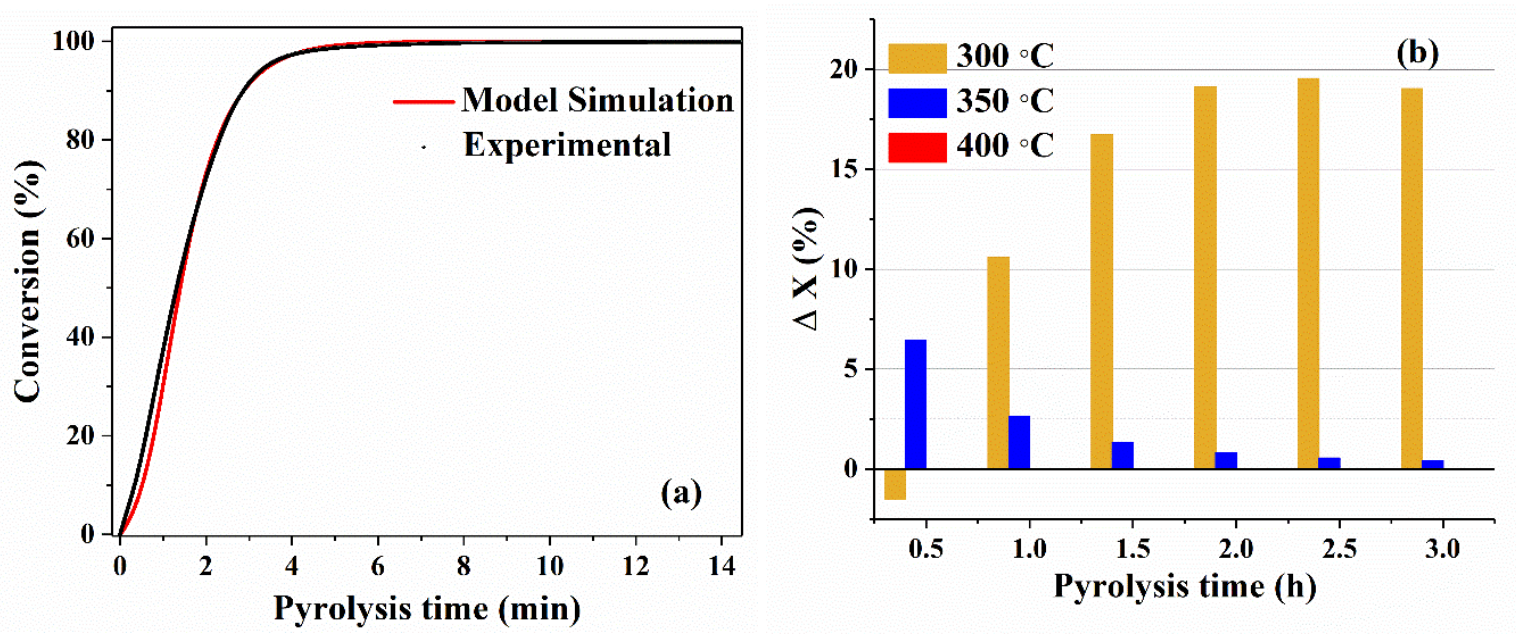

Fig. 3.5 - Simulation and isothermal TGA experimental data of the EGDMA crosslinked PMMA pyrolysis conversion as a function of time at $400{ }^{\circ} \mathrm{C}$ (a) and absolute differences between model prediction and experimental mass conversions, $\Delta X$, obtained by isothermal TGA experiments as a function of time at 300,350 and $400{ }^{\circ} \mathrm{C}(\mathrm{b})$.

\section{Conclusions}

This work has presented the modelling of the depolymerisation kinetics involved in the thermal pyrolysis of ethylene glycol dimethacrylate (EGDMA) crosslinked PMMA from industrial dental waste for the first time. Kinetics parameters and their statistical significance have been determined by using eight non-isothermal TGA experiments with heating rates varying between 5 and $50{ }^{\circ} \mathrm{C} / \mathrm{min}$. Our analysis indicates that the mechanism of depolymerisation of EGDMA crosslinked PMMA is likely to follow a consecutive reaction pathway involving two steps, since this hypothesis allowed for the estimation of kinetic parameters presenting low or non-significant linear correlation coefficients with the heating rate. Therefore, it has been shown that the kinetic model structure may contribute for minimising heat transfer effects on the estimated kinetic parameters. The developed kinetic model - containing five kinetic parameters only - was able to predict well all non-isothermal TGA runs, and was validated against isothermal TGA experiments at $400{ }^{\circ} \mathrm{C}$. 


\section{Acknowledgements}

The authors thank CAPES (Coordernação de Aperfeiçoamento de Pessoa de Nível Superior), CNPq (Conselho Nacional de Desenvolvimento Científico e Tecnológico) and Dentsply for financial support and scholarships.

\section{References}

[1] A. Quye, Quality Matters for Historical Plastics: The Past-Making of Cellulose Nitrates for Future Preservation, Cah. François Viète. 2 (2017) 45-65.

[2] R. Geyer, J.R. Jambeck, K.L. Law, Production, uses, and fate of all plastics ever made, Sci. Adv. 3 (2017) 5. doi:10.1126/sciadv.1700782.

[3] A. Rahimi, J.M. García, Chemical recycling of waste plastics for new materials production, Nat. Rev. Chem. 1 (2017) 0046. doi:10.1038/s41570-017-0046.

[4] PlasticsEurope, Plastics-the Facts 2017, https://www.plasticseurope.org, 2018 (Accessed 06 August 2018).

[5] S. Kumar, A.K. Panda, R.K. Singh, A review on tertiary recycling of high-density polyethylene to fuel, Resour. Conserv. Recycl. 55 (2011) 893-910. doi:10.1016/j.resconrec.2011.05.005.

[6] ASTM International, Standard Guide for Development of ASTM Standards Relating to Recycling and Use of Recycled Plastics, D 5033 (2000) 1-6.

[7] B.F. Sasse, G. Emig, Chemical Recycling of Polymer Materials, Chem. Eng. Technol. 21 (1998) 777-789. doi:10.1002/(SICI)1521-4125(199810)21:10<777::AID- 


\section{CEAT777>3.0.CO;2-L}

[8] E. Esmizadeh, S. Khalili, A. Vahidifar, G. Naderi, C. Dubois, Waste Polymethyl Methacrylate (PMMA): Recycling and high-yield monomer recovery, in: M. L., K. O., K. B. (Eds.), Handb. Ecomater., Springer, 2018: pp. 1-33. doi:10.1007/978-3-31968255-6_164.

[9] Y. Kikuchi, M. Hirao, T. Ookubo, A. Sasaki, Design of recycling system for poly(methyl methacrylate) (PMMA). Part 1: Recycling scenario analysis, Int. J. Life Cycle Assess. 19 (2014) 120-129. doi:10.1007/s11367-013-0624-y.

[10] G. Odian, Principles of Polymerization, 4º, Wiley-Interscience, New York, 2004. doi:10.1017/CBO9780511813535.

[11] G. Lopez, M. Artetxe, M. Amutio, G. Elordi, R. Aguado, M. Olazar, J. Bilbao, Recycling poly-(methyl methacrylate) by pyrolysis in a conical spouted bed reactor, Chem. Eng. Process. Process Intensif. 49 (2010) 1089-1094. doi:10.1016/j.cep.2010.08.002.

[12] U. Ali, K.J.B.A. Karim, N.A. Buang, A Review of the Properties and Applications of Poly (Methyl Methacrylate) (PMMA), Polym. Rev. 55 (2015) 678-705. doi:10.1080/15583724.2015.1031377.

[13] K. Charmondusit, L. Seeluangsawat, Recycling of poly(methyl methacrylate) scrap in the styrene-methyl methacrylate copolymer cast sheet process, Resour. Conserv. Recycl. 54 (2009) 97-103. doi:10.1016/j.resconrec.2009.07.005.

[14] A.Z.V. E. ŠuŠterŠic, M. TuŠsar, Asphalt concrete modification with waste PMMA/ATH, Mater. Struct. 47 (2014) 1817-1824. doi:DOI 10.1617/s11527-0130152-z. 
[15] S.S. Suresh, S. Mohanty, S.K. Nayak, Investigation into the mechanical and thermal properties of poly(methyl methacrylate) recovered from light guidance panels with a focus on future remanufacturing and sustainable waste management, J. Remanufacturing. 7 (2017) 217-233. doi:10.1007/s13243-017-0041-7.

[16] A.R. Prado, A.G. Leal-Junior, C. Marques, S. Leite, G.L. de Sena, L.C. Machado, A. Frizera, M.R.N. Ribeiro, M.J. Pontes, Polymethyl methacrylate (PMMA) recycling for the production of optical fiber sensor systems, Opt. Express. 25 (2017) 30051-30060. doi:10.1364/oe.25.030051.

[17] R.S. Braido, L.E.P. Borges, J.C. Pinto, Chemical recycling of crosslinked poly(methyl methacrylate) and characterization of polymers produced with the recycled monomer, J. Anal. Appl. Pyrolysis. 132 (2018) 47-55. doi:10.1016/j.jaap.2018.03.017.

[18] D.S. Achilias, Chemical recycling of poly(methyl methacrylate) by pyrolysis. Potential use of the liquid fraction as a raw material for the reproduction of the polymer, Eur. Polym. J. 43 (2007) 2564-2575. doi:10.1016/j.eurpolymj.2007.02.044.

[19] W. Kaminsky, C. Eger, Pyrolysis of filled PMMA for monomer recovery, J. Anal. Appl. Pyrolysis. 58-59 (2001) 781-787. doi:10.1016/S0165-2370(00)00171-6.

[20] T. Kashiwagi, A. Inaba, J.E. Brown, K. Hatada, T. Kitayama, E. Masuda, Effects of Weak Linkages on the Thermal and Oxidative Degradation of Poly (methyl methacrylates), Macromolecules. 19 (1986) 2160-2168. doi:10.1021/ma00162a010.

[21] L.E. Manring, Thermal Degradation of Saturated Poly(Methyl Methacrylate), Macromolecules. 21 (1988) 528-530. doi:10.1021/ma00180a046.

[22] L.E. Manring, Thermal degradation of Poly(methyl methacrylate). 2. VinylTerminated Polymer, Macromolecules. 22 (1989) 2673-2677. 
doi:10.1021/ma00196a024.

[23] G.M. Manring, L.E., Sogah, D. Y., Cohen, Thermal degradation of Poly(methyl methacrylate). 3. Polymer with Head-to-Head Linkages, Macromolecules. 22 (1989) 4652-4654. doi:10.1021/ma00202a048.

[24] L.E. Manring, Thermal Degradation of Poly(methyl methacrylate). 4. Random SideGroup Scission, Macromolecules. 24 (1991) 3304-3309. doi:10.1021/ma00011a040.

[25] J. Rychlý, J. Pavlinec, Thermal degradation of free radically prepared poly(methyl methacrylate). A nonisothermal weight loss study, Polym. Degrad. Stab. 28 (1990) 115. doi:10.1016/0141-3910(90)90048-C.

[26] K. Min, M. Silberstein, N.R. Aluru, Crosslinking PMMA: Molecular dynamics investigation of the shear response, J. Polym. Sci. Part B Polym. Phys. 52 (2014) 444449. doi:10.1002/polb.23437.

[27] M. Ferriol, A. Gentilhomme, M. Cochez, Thermal degradation of poly (methyl methacrylate)(PMMA): modelling of DTG and TG curves, Polym. Degrad. Stab. 79 (2003) 271-281. doi:10.1016/S0141-3910(02)00291-4.

[28] T. Fateh, F. Richard, T. Rogaume, P. Joseph, Experimental and modelling studies on the kinetics and mechanisms of thermal degradation of polymethyl methacrylate in nitrogen and air, J. Anal. Appl. Pyrolysis. 120 (2016) 423-433. doi:10.1016/j.jaap.2016.06.014.

[29] F.S. Toniolo, E. Barbosa-Coutinho, M. Schwaab, I.C.L. Leocadio, R.S. Aderne, M. Schmal, J.C. Pinto, Kinetics of the catalytic combustion of diesel soot with $\mathrm{MoO}_{3} / \mathrm{Al}_{2} \mathrm{O}_{3}$ catalyst from thermogravimetric analyses, Appl. Catal. A Gen. 342 (2008) 87-92. doi:10.1016/j.apcata.2008.03.004. 
[30] M. Schwaab, F.M. Silva, C.A. Queipo, A.G. Barreto, M. Nele, J.C. Pinto, A new approach for sequential experimental design for model discrimination, Chem. Eng. Sci. 61 (2006) 5791-5806. doi:10.1016/j.ces.2006.04.001.

[31] S. Da Ros, M. Schwaab, J.C. Pinto, Parameter Estimation and Statistical Methods, Ref. Modul. Chem. Mol. Sci. Chem. Eng. (2017). doi:10.1016/B978-0-12-409547-2.139186.

[32] M. Schwaab, J.C. Pinto, Optimum reference temperature for reparameterization of the Arrhenius equation. Part 1: Problems involving one kinetic constant, Chem. Eng. Sci. 62 (2007) 2750-2764. doi:10.1016/j.ces.2008.03.010.

[33] M. Schwaab, L.P. Lemos, J.C. Pinto, Optimum reference temperature for reparameterization of the Arrhenius equation. Part 2: Problems involving multiple reparameterizations, Chem. Eng. Sci. 63 (2008) 2895-2906. doi:10.1016/j.ces.2008.03.010.

[34] J.A. Conesa, A. Marcilla, J.A. Caballero, R. Font, Comments on the validity and utility of the different methods for kinetic analysis of thermogravimetric data, J. Anal. Appl. Pyrolysis. 58-59 (2001) 617-633. doi:10.1016/S0165-2370(00)00130-3.

[35] L.R. Petzold, A description of DASSL: A Differential/Algebraic system solver, in: IMACA World Congr., Montreal, 1982: pp. 1-11. doi:https://www.osti.gov/servlets/purl/5882821.

[36] R. Kennedy, J., Eberhart, Particle Swarm Optimization, in: Proc. IEEE Int. Conf. Neural Networks, Perth, 1995: pp. 1942-1948. doi:10.1007/978-3-319-93073-2_6.

[37] T.J.S. F. B. Noronha, J. C. Pinto, J. L. Monteiro, M. W. Lobao, ESTIMA: Um Pacote Computacional para Estimação de Parâmetros e Projeto de Experimentos, Rio de 
Janeiro, 1993.

[38] M. Schwaab, E.C. Biscaia, J.L. Monteiro, J.C. Pinto, Nonlinear parameter estimation through particle swarm optimization, Chem. Eng. Sci. 63 (2008) 1542-1552. doi:10.1016/j.ces.2007.11.024.

[39] J.C.P. M. Schwaab, Analise de Dados Experimentais I - Fundamentos de Estatística e Estimação de Parâmetros, e-papers, Rio de Janeiro, 2007.

[40] W.G. Box, G.P., Hunter, J.S., Hunter, Statistics for Experimenters - Design, Innovation, and Discovery, Second, Wiley-Interscience, John Wiley \& Sons, Inc., New Jersey, 2005. doi:10.1017/S1742170510000062.

[41] T. Hirata, T. Kashiwagi, J.E. Brown, Thermal and Oxidative Degradation of Poly(methyl methacrylate): Molecular Weight, Macromolecules. 18 (1985) 14101418. doi:10.1021/ma00144a003.

[42] M.M. and R.A. Gad, Behavior of PMMA Denture Base Materials Containing Titanium Dioxide Nanoparticles : A Literature Review, Int. J. Biomater. 2019 (2019). doi:https://doi.org/10.1155/2019/6190610 Review.

[43] T. Paiva, L. Vieira, P. Melo, M. Nele, J.C. Pinto, In Situ Incorporation of Praziquantel in Polymer Microparticles through Suspension Polymerization for Treatment of Schistosomiasis, Macromol. React. Eng. 13 (2019) 1-12. doi:10.1002/mren.201800064.

[44] T.F. Paiva, Development of smart polymeric microparticles for the modified release of Praziquantel for the treatment of schistosomiasis, Federal University of Rio de Janeiro (UFRJ), 2019. 